\title{
Marshall syndrome: a condition resembling congenital syphilis
}

\author{
B A ONile, A ROTOWA, A O OSOBA, AND O K Alausa \\ From the Special Treatment Clinic, University College Hospital, Ibadan, Nigeria
}

SUMMARY Marshall syndrome (ectodermal dysplasia) was diagnosed in a 14-year-old boy and is thought to be the first case reported from West Africa. Because of the saddle-nose deformity and bilateral cataracts all patients suspected of having congenital syphilis should be investigated for ocular or auditory defects, which would confirm the diagnosis of ectodermal dysplasia.

\section{Introduction}

Ectodermal dysplasia, otherwise known as Marshall syndrome, ${ }^{1}$ involves anomalous formation of the ectoderm and its accessory structures. ${ }^{2}$ The most frequently encountered features are congenital abnormalities or absence of hair, teeth, nails, and skin glands. In severe cases the olfactory epithelium and nerve, anterior lobe of the hypophysis, crystalline lens of the eye and vitreous, the auditory vesicle, and the inner ear mechanism may also be affected. ${ }^{3-5}$ Lachrymal anomalies have also been described among other ocular manifestations. ${ }^{6}$

\section{Case report}

A 14-year-old schoolboy was referred to the sexually transmitted diseases clinic of the University College Hospital, Ibadan, Nigeria, by an ophthalmologist because syphilis was suspected. The patient complained of progressive loss of vision for about four years and defective hearing. He was the eldest of three siblings; the other two children had no similar complaints. There was no known history of syphilis in the family.

\section{CLINICAL FINDINGS}

On examination he had scanty scalp hair and a patch of baldness (fig 1). He also had a depressed bridge of the nose (fig 2) and loss of two upper central incisors (fig 3). The eyelashes and eyebrows were also sparse. He had bilateral optic atrophy, myopia, and some defective hearing. The cardiovascular and central

Address for reprints: Dr B A Onile, Faculty of Health Sciences, University of Ilorin, Ilorin, Nigeria.

Accepted for publication 7 October 1980

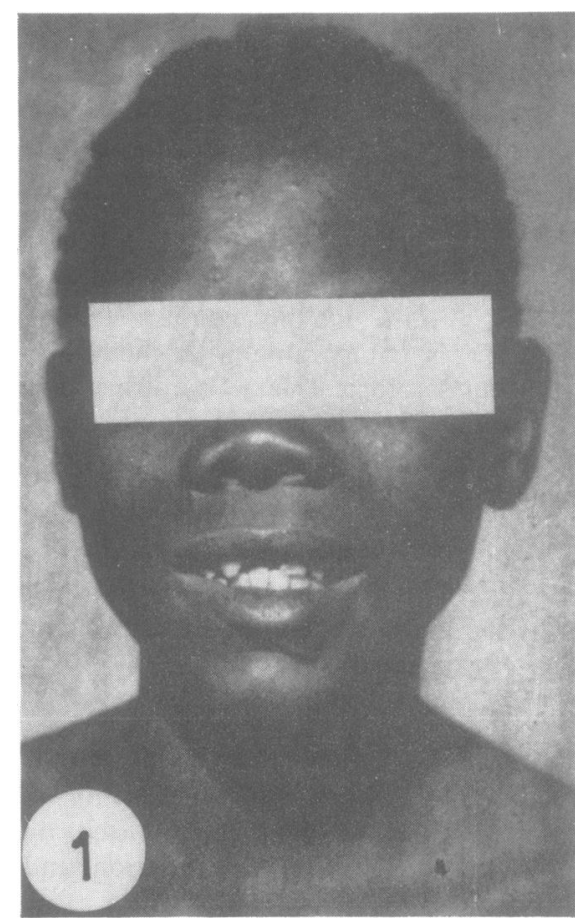

FIG 1 Scanty scalp hair with a patch of baldness

nervous systems were normal. A provisional clinical diagnosis of congenital syphilis was made because of the saddle-nose deformity.

OTHER INVESTIGATIONS

The Venereal Disease Research Laboratory (VDRL) and Treponema pallidum haemagglutination 


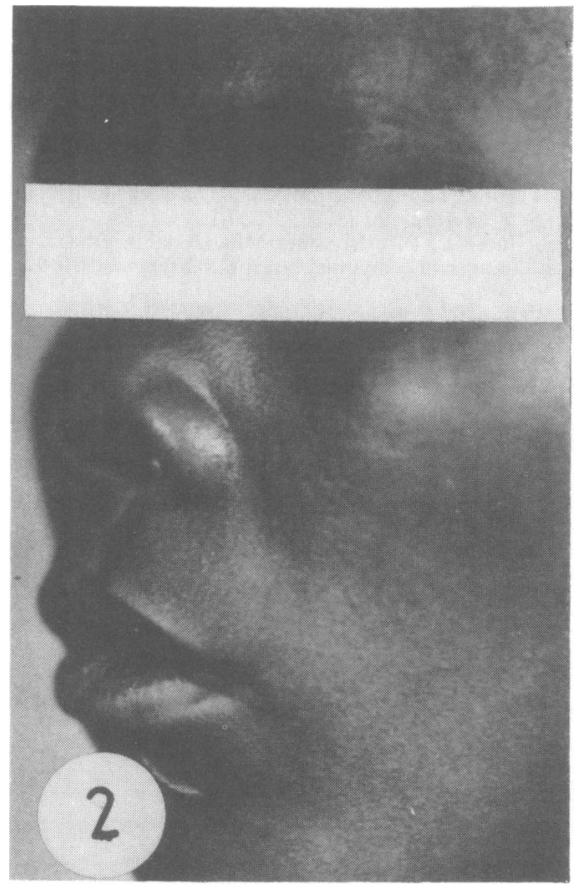

FIG 2 Saddle-nose deformity

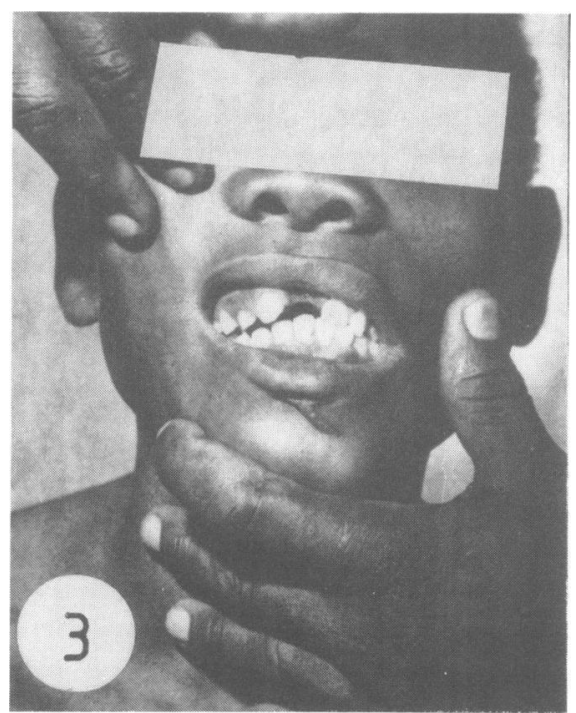

FIG 3 Dental anomalies; loss of the upper central incisors

(TPHA) tests both gave negative results on two successive occasions a month apart. Radiological examination of the long bones showed no abnormal periosteal calcification and no abnormality of the metaphyses.
The diagnosis was later changed to ectodermal dysplasia (Marshall syndrome) since further investigations did not support our earlier clinical diagnosis of congenital syphilis. The latter diagnosis was later confirmed by Dr R D Catterall (personal communication, 1979). Attempts at further investigation of the family and determination of the type of hearing loss were not possible because the patient absconded.

\section{Discussion}

Marshall ${ }^{2}$ reported a family of seven individuals over three generations who showed the following abnormalities: congenital and juvenile cataracts, some of which showed spontaneous maturation and absorption while others showed spontaneous luxation with complications; basic myopia; fluid vitreous; defective hearing; defect of nose and associated facies; and other evidence of incomplete examples of anhidrotic ectodermal dysplasia.

Ruppert et $a l^{7}$ described hereditary hearing loss with saddle nose and myopia in a father and daughter, who had sensorineural deafness with a saddle-nose defect, severe myopia, and juvenile cataracts. The saddle-nose defect could be traced vertically in three preceding generations although no auditory or visual defects had been detected. It was postulated that this syndrome was a genetic disease, transmitted as an autosomal dominant with variable expressions. However, Kerr et $a l^{8}$ believed that the syndrome was transmitted as an X-linked recessive trait with the male members showing the entire picture and the female members only a few signs, being mainly carriers.

Zullweger et $a l^{1}$ described a family of four cases of Marshall syndrome, who also showed saddle nose, sensorineural hearing loss, high-grade myopia, and congenital or presenile cataracts. The first documented case in an Afrian negro was reported by Slee in $1976^{9}$ and showed lachrymal epiphora.

This case is the first seen in West Africa. Unfortunately we could not investigate the family in detail to determine the hereditary nature or the type of hearing loss in the patient before he absconded. Nevertheless, the case is reported because the presentation could, and did, pose a problem of diagnosis from congenital syphilis because of the saddle-nose deformity and bilateral cataracts. Congenital syphilis causes keratitis profunda (interstitial keratitis) and not cataracts. ${ }^{10}$ While interstitial keratitis affects the deeper layers of the cornea, cataracts affect the lens. Serological tests for syphilis (VDRL) and specific treponemal antibody tests (such as the TPHA) performed on at least two occasions with a month's interval usually give positive results in congenital syphilis. Family 
investigations will also show that the mother either has syphilis or has been treated for it in the past. It is also important that all patients suspected of having congenital syphilis should be referred to an ophthalmologist and otorhinolaryngologist to detect any ocular or auditory involvement.

We are grateful to Dr R D Catterall, president of the International Union against Venereal Diseases and Treponematoses, for his helpful advice on the investigation of this patient.

\section{References}

1. Zullweger H, Smith JK, Grutzner P. The Marshall syndrome: Report of a new family. J Pediatr 1974;84:868-71.

2. Marshall D. Ectodermal dysplasia. Am J Ophthalmol 1958; 45: 143-56.
3. Clouston HR. The major forms of hereditary ectodermal dysplasia. Can Med Assoc J 1939; 40: 1-6.

4. Elligson RJ. Major hereditary ectodermal dysplasia. J Pediatr 1951;38: 191-8.

5. Horne GO. Differential diagnosis of facial and dental manifestations in congenital syphilis. Arch Dis Child 1954;29: 123-5.

6. Liakos GM. Anhidrotic ectodermal dysplasia with lachrymal anomalies. Br J Ophthalmol 1979; 63:520-1.

7. Ruppert ES, Buerk E, Pfordsreasher MF. Hereditary hearing loss with saddle-nose and myopia. Arch Otolaryngol 1970;92: 95-8.

8. Kerr GB, Wells RS, Cooper KE. Gene effect in carriers of anhidrotic ectodermal dysplasia. $J$ Med Genet 1966; 3:169-76.

9. Slee PHTJ. Anhidrotic ectodermal dysplasia in an African Negro family. Trans $R$ Soc Trop Med Hyg 1976; 70:252-3.

10. Schofield CBS. Congenital syphilis. In: Sexually Transmitted Diseases, 3rd ed London: Churchill Livingstone, 1979;113-21. 